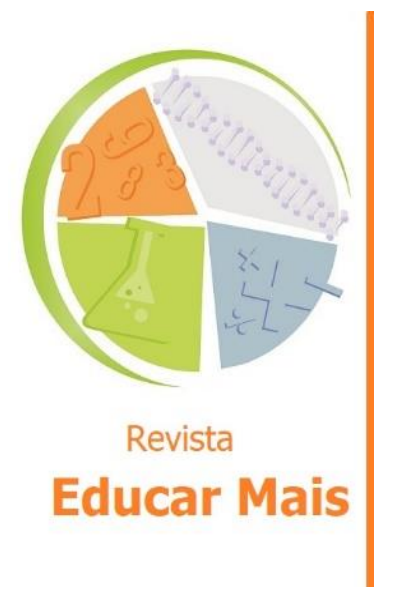

\title{
Decolonizar é preciso: pensando a escola e o currículo para a superação do racismo
}

\author{
Decolonizing is necessary: thinking the school and the curriculum to \\ overcome racism
}

\section{Es necesario descolonizar: pensar en la escuela y el currículo para superar el racismo}

Dheysa Paulo Parente ${ }^{1}$; Sheila de Sousa Teodosio²; Francisco Régis Vieira Alves ${ }^{3}$

\section{RESUMO}

Uma visão estrutural do racismo permite a compreensão das complexas e históricas desigualdades que marcam as relações étnico-raciais no Brasil. A partir dela é possível visualizar como o racismo vem se reproduzindo e reconhecer a necessidade do engajamento coletivo para sua superação. Admitindo que a escola tem reproduzido o racismo, mas que é potente espaço para sua superação, este artigo objetiva apresentar a importância da efetivação de uma educação antirracista por meio de um currículo decolonial. Partindo de uma abordagem qualitativa, foram usados enquanto procedimentos para desenvolvimento deste estudo, a pesquisa bibliográfica e documental. Conclui-se que uma escola comprometida com a superação das desigualdades raciais deve repensar as práticas escolares e vivenciar um fazer pedagógico norteado por um currículo decolonial,um currículo que parta de outros referenciais epistêmicos, que dê voz aos silenciados pela dominação colonial, que apresente outras formas de ser e estar no mundo, um currículo que rompa com os parâmetros europeus e consequentemente com a colonialidade reprodutora do racismo.

Palavras-chave: Racismo; Escola; Currículo decolonial.

\begin{abstract}
A structural view of racism allows us to understand the complex and historical inequalities that mark ethnoracial relations in Brazil. From it, it is possible to visualize how racism has been reproducing itself and to recognize the need for collective engagement to overcome it. Admitting that the school has reproduced racism, but that it is a powerful space for its overcoming, this article aims to present the importance of an anti-racist education through a decolonial curriculum. Based on a qualitative approach, the procedures used to develop this study were bibliographic and documental research. We conclude that a school committed to overcoming racial inequalities should rethink the school practices and experience a pedagogical practice guided by a decolonial curriculum, a curriculum that starts from other epistemic references, which gives voice to those silenced by colonial domination, which presents other ways of being and being in the world, a curriculum that breaks with the European parameters and consequently with the coloniality that reproduces racism.
\end{abstract}

Keywords: Racism; School; Decolonial curriculum.

\footnotetext{
${ }^{1}$ Mestranda em Educação Profissional e Tecnológica (ProfEPT) pelo Instituto Federal de Educação Ciência e Tecnologia do estado do Ceará (IFCE), Fortaleza/CE - Brasil. E-mail: dheysaparente@yahoo.com.br

${ }^{2}$ Mestranda em Educação Profissional e Tecnológica (ProfEPT) pelo Instituto Federal de Educação Ciência e Tecnologia do estado do Ceará (IFCE), Fortaleza/CE - Brasil. E-mail: sheilateodosio@gmail.com

${ }^{3}$ Doutor em Educação com ênfase em Educação Matemática e professor titular do Instituto Federal de Educação Ciência e Tecnologia do estado do Ceará (IFCE) nos programas de pós-graduação PROFEPT/IFCE e PGECM/IFCE, coordenador do doutorado acadêmico em REDE RENOEN/IFCE e bolsista de produtividade em Pesquisa do CNPQ-PQ2, Fortaleza/CE - Brasil. E-mail: fregis@ifce.edu.br
} 


\section{RESUMEN}

Una visión estructural del racismo permite comprender las complejas e históricas desigualdades que marcan las relaciones étnico-raciales en Brasil. A partir de ella, es posible visualizar cómo se ha ido reproduciendo el racismo y reconocer la necesidad de un compromiso colectivo para superarlo. Admitiendo que la escuela ha reproducido el racismo, pero que es un espacio poderoso para su superación, este artículo pretende presentar la importancia de una educación antirracista a través de un currículo decolonial. Basado en un enfoque cualitativo, se utilizaron la investigación bibliográfica y documental como procedimientos para desarrollar este estudio. Concluimos que una escuela comprometida con la superación de las desigualdades raciales debe repensar las prácticas escolares y experimentar una práctica pedagógica guiada por un currículo decolonial, un currículo que parta de otros referentes epistémicos, que dé voz a los silenciados por la dominación colonial, que presente otras formas de ser y estar en el mundo, un currículo que rompa con los parámetros europeos y en consecuencia con la colonialidad reproductora del racismo.

Palabras clave: Racismo; Escuela; Currículo decolonial.

\section{INTRODUÇÃO}

O racismo perpassa toda a estrutura que organiza a sociedade brasileira afetando tanto as condições materiais objetivas da vida dos sujeitos quanto suas subjetividades, e falar sobre ele implica tanto numa abordagem histórica, quanto pensar possibilidades para superá-lo, visto que $56,2 \%$ da população brasileira é composta por negros ${ }^{4}$, ou seja, mais da metade dos habitantes do país são diretamente afetados pelo racismo.

Construído a partir de relações de poder que hierarquizaram seres humanos tendo por base o critério racial, o Brasil é alicerçado sobre históricas desigualdades que se atualizam e continuam a se reproduzir. Para superá-las, é necessário a vivência de um presente autocrítico, que olhe para o passado e se comprometa com o porvir. Neste projeto de futuro, o papel da educação é fundamental.

Partindo de uma abordagem qualitativa, o presente trabalho trata-se de uma revisão bibliográfica e documental que objetiva apresentar a importância da efetivação de uma educação antirracista por meio de um currículo decolonial. Conforme Fontana (2018, p. 66), a pesquisa bibliográfica "vinculase à leitura, análise e interpretação de livros, periódicos, manuscritos, relatórios, teses, monografias", neste caso, foi realizado um levantamento extensivo de artigos, teses e livros que discorrem sobre a temática abordada, selecionando os mais relevantes para desenvolver a discussão.

Ainda, foram utilizados documentos públicos, como leis, decretos e informações constantes em bancos de dados de órgãos governamentais do IBGE e do Ministério da Mulher, da Família e dos Direitos Humanos. Para Fontana (2018) a pesquisa documental compreende o manuseio e análise de documentos e/ou materiais históricos, institucionais e associativos, públicos e privados.

O trabalho inicia-se com a definição do que é racismo estrutural a partir das ideias de Almeida (2019), pois entende-se que compreender como o racismo se estrutura na sociedade brasileira é fundamental para a tomada de consciência, responsabilização e ação social. Prossegue-se localizando a escola dentro dessa estrutura e analisando sua posição conflituosa, pois enquanto instituição social, reproduz o racismo, mas pode ser espaço potente para combatê-lo.

\footnotetext{
${ }^{4}$ De acordo com o Instituto Brasileiro de Geografia e Estatística (IBGE), a população negra brasileira é composta pelo somatório dos autodeclarados pretos ou pardos.
} 
Para a superação do racismo no âmbito escolar é necessário instrumentalizá-la, para isso apresentase a Lei no 10.639/2003, a Lei de Diretrizes e Bases da Educação (LDB 9.394/96) e as Diretrizes Curriculares Nacionais para a Educação das Relações Étnico-Raciais (2004), instrumentos normativos que, dentre outros, regulamentam a inserção da história e cultura afro-brasileira no currículo escolar.

Por fim são feitas reflexões curriculares a partir das noções de colonialidade e decolonialidade com vistas a um repensar e refazer pedagógico que rompam com os padrões eminentemente europeus que historicamente tem se estabelecido na educação brasileira.

\section{RACISMO ESTRUTURAL}

Para combater o racismo é necessário compreender como ele se apresenta na sociedade brasileira, haja vista que, como ressalta Almeida (2019), ele é estrutural, ou seja, faz parte da ordem social. Uma estrutura que destina um lugar de vantagem ou desvantagem na sociedade dependendo dos critérios cor/raça ao qual o indivíduo pertença. Nesse sentido, são destacados quatro aspectos que se constituem enquanto cerne do racismo estrutural: a Ideologia, o Direito, a Política e a Economia.

A Ideologia é uma prática utilizada para reforçar a representação que as pessoas negras ocupam no imaginário social; locais de invisibilidade, subalternização e silenciamento. Assim, é naturalizado que os negros realizem serviços braçais, ocupem vagas de trabalho mal remuneradas e precarizadas e que não estejam em espaços de poder. Imaginário reforçado pelos meios de comunicação, indústria cultural e pela escola.

Para exemplificar podem ser citados: a cristalização de uma "vocação natural" das mulheres negras para o serviço doméstico ou sua hipersexualização, e a personalidade dos homens negros inclinada à violência e à criminalidade, ou seja, o estereótipo do homem negro criminoso. Nas escolas é notória a influência da ideologia que valoriza saberes eurocêntricos, visto que o currículo ainda silencia a história, cultura, memória e as mais diversas contribuições da população negra na formação nacional.

Ao ser lançado um olhar histórico sobre o conjunto de leis brasileiras é possível perceber como o Direito atuou para legitimar práticas excludentes e repressoras, como a escravização negra, que estava dentro da legalidade tornando possível uma pessoa ser minorada à condição de propriedade de outra. A coisificação de pessoas negras pode ser observada na consolidação das leis civis realizada por Freitas (2003) que ao apresentar a Lei de 20 de junho de 1774, traz a classificação dos escravizados dentro da categoria de um bem móvel, nesse caso, um bem semovente, ou seja, que se move por si só. Considerados bens, objetos, coisas, os escravizados eram propriedades de outrem.

No contexto pós-abolicionista houve a ausência de políticas públicas que visassem à inclusão dos exescravizados à sociedade e as leis atuaram para marginalizar e criminalizar essa população. Para corroborar a afirmativa são apresentados o Decreto-Lei no 145, de 11 de julho de 1893 e o Decreto no 847 , de 11 de outubro de 1890. O primeiro punia com prisão, vadios, vagabundos e capoeiras encontrados na capital federal; e o segundo criminalizava a capoeira.

Se por um lado as leis atuaram para criminalizar os corpos e práticas negras, por outro havia um desejo latente de branquear a população, o que pode ser comprovado por meio do Decreto Federal no 528, de 28 de junho de 1890. Através dele, o governo federal normatizou a imigração com um recorte racial. Segue o que estipulava o artigo $1^{\circ}$ : 
É inteiramente livre a entrada, nos portos da Republica, dos individuos válidos e aptos para o trabalho, que não se acharem sujeitos á acção criminal do seu paiz, exceptuados os indigenas da Asia, ou da Africa que sómente mediante autorização do Congresso Nacional poderão ser admittidos de accordo com as condições que forem então estipuladas (BRASIL, 1890).

Aqui é possível visualizar a cristalização do ideário de superioridade racial e institucionalização do racismo por parte do Estado, pois excluía a entrada de asiáticos e africanos. Este decreto regulamentava, dentre outros benefícios aos imigrantes, o pagamento de passagens e facilidades para aquisição de moradias e ferramentas de trabalho. Enquanto isso, os ex-escravizados foram entregues à própria sorte.

Esse breve histórico mostra como o Estado se utilizou do Direito para excluir, marginalizar e subalternizar a população negra, pois a "ascensão ao poder de grupos políticos racistas colocou o Direito à serviço de projetos de discriminação sistemática, segregação racial e até extermínio" (ALMEIDA, 2019 p. 135-136). São relações de poder que hoje se materializam nas abordagens violentas da polícia e no encarceramento em massa da população negra, por exemplo.

A dimensão Política do racismo está intimamente relacionada ao Estado, visto que no sistema capitalista, a organização política da sociedade é exercida por ele, que atua para manter a ordem. Numa perspectiva estrutural, o Estado é visto enquanto mediador das relações sociais, que são marcadas por conflitos. Essa perspectiva tem suas raízes forjadas a partir da década de 1930, nesse sentido, Almeida (2019, p. 107) destaca:

A partir de 1930, a necessidade de unificação nacional e a formação de um mercado interno, em virtude do processo de industrialização, dão origem a toda uma dinâmica institucional para a produção do discurso da democracia racial, em que a desigualdade racial - que se reflete no plano econômico - é transformada em diversidade cultural e, portanto, tornada parte da paisagem nacional.

Com vistas à consolidação de um projeto nacional, é perceptível a transformação da desigualdade em diversidade. Se solidifica, a partir de então, o mito da democracia racial, que parte do pressuposto de que todos os cidadãos possuem plena igualdade, independente de etnia ou raça, pois são o resultado da miscigenação ocorrida entre europeus, indígenas e africanos.

Ao negar conflitos, o mito da democracia racial serve para acalmar as tensões decorrentes das relações étnico-raciais e alimenta a ideia de que não há racismo no país. Ribeiro $(2019$, p. 18) adverte que "é preciso identificar os mitos que fundam as peculiaridades do sistema de opressão operado aqui, e certamente o da democracia racial é o mais conhecido e nocivo deles". Sob o signo da igualdade jurídica, as condições desiguais que marcam as relações étnico-raciais são desconsideradas e ao indivíduo é imputada toda a responsabilidade por seu sucesso ou fracasso.

Nesse sentido, o discurso da meritocracia é impulsionado, e a população negra, a qual foi negada uma reparação histórica, continua largada à própria sorte. É neste discurso meritocrático que o racismo e a economia se encontram. Falar sobre essa interseção é falar sobre desigualdade, e para compreendê-la, é necessário reconhecer os conflitos sociais, que têm raízes históricas e perduram até hoje, refletindo-se nas condições materiais de vida da população negra.

Ao analisar a situação da população negra no contexto pós-abolição, Carvalho (2004) afirma que ela foi privada de terra, emprego e educação, realidade que, segundo o autor, continua a se reproduzir, pois os negros permanecem ocupando os piores indicadores de qualidade de vida, sendo a parcela 
populacional com menor acesso à educação, que ocupa os empregos menos qualificados, por consequência, mal remunerados e apresentam os piores índices de ascensão social.

Essa realidade segue ocorrendo. Isso fica evidente ao serem analisados os dados da Síntese de Indicadores Sociais da Pesquisa Nacional por Amostra de Domicílios Contínua (PNAD Contínua), que revelam a disparidade das relações de trabalho com base no fator racial, pois a população negra brasileira, somatório de pretos e pardos, correspondem a $56,2 \%$ da população e possuem as piores condições socioeconômicas (IBGE, 2019).

De acordo com os dados, a taxa de desocupação dessa população foi de $13,6 \%$, enquanto a da população branca foi de $9,2 \%$. Pretos ou pardos ganham em média $69,3 \%$ menos que os brancos por hora trabalhada. $O$ percentual de pretos e pardos que se declararam pobres ou extremamente pobres foi de respectivamente $32,3 \%$ e $8,9 \%$ superando o percentual de $14,7 \%$ da população branca que se declarou pobre e $3,4 \%$ se declararam extremamente pobre. Os dados ainda revelam mais um agravante, 39,8\% das pessoas extremamente pobres são mulheres pretas ou pardas (IBGE, 2019).

A pesquisa também revelou que a maior população empregada com rendimentos inferiores à média salarial do país em 2019, ocupando postos de trabalho que se caracterizam pela informalidade, foi de pretos ou pardos. Desses, $62,7 \%$ estavam trabalhando na agropecuária e $66,6 \%$ nos serviços domésticos e construção. Já os serviços cujos rendimentos médios são bastante superiores à média estavam ocupados com uma maior participação de pessoas brancas (IBGE, 2019).

Os dados apresentados corroboram as ideias de Almeida (2019), que aponta duas conclusões a partir da análise do racismo do ponto de vista econômico-estrutural:

1- O racismo se manifesta no campo econômico de forma objetiva, como quando as políticas econômicas estabelecem privilégios para um grupo racial dominante ou prejudicam minorias. Um exemplo disso é a tributação. Em países como o Brasil, em que a tributação é feita primordialmente sobre salário e consumo - que pesa principalmente sobre os mais pobres e assalariados -, em detrimento da tributação sobre patrimônio e renda, que incidiria sobre os mais ricos - a carga tributária tornase um fator de empobrecimento da população negra, especialmente das mulheres, visto que estas são as que recebem os menores salários [...]

2- O racismo faz com que a pobreza seja ideologicamente incorporada quase que como uma condição 'biológica' de negros e indígenas, naturalizando a inserção no mercado de trabalho de grande parte das pessoas identificadas com estes grupos sociais com salários menores e condições de trabalho precárias (ALMEIDA, 2019, p. 171-172).

Ou seja, o racismo estrutura e é estruturado pela sociedade, pois há uma ideologia formada acerca do negro que é vivenciada no cotidiano. Essas representações são reforçadas pela mídia, reproduzidas nas relações interpessoais e nas instituições, como escolas, universidades, família, trabalho, igreja e pelo próprio Estado.

Ao refletir sobre racismo estrutural, Ribeiro (2019) afirma que o mito da relação harmônica das três raças internalizou nos sujeitos a inexistência de conflitos e consequentemente, de racismo, por isso que a maioria da população brasileira nega que seja racista, embora admita que há racismo no Brasil. Isso demonstra a tentativa de transferir para o outro que "ele" é preconceituoso, não "eu".

Diante dessa visão harmônica que se concebeu acerca da formação do povo brasileiro sem que tenha sido feita a devida problematização, a negação do racismo foi gestada; e diante de toda construção 
histórica, social e simbólica acerca do negro, o racismo faz parte do cotidiano, pois está impregnado nas relações sociais manifestando-se de forma consciente, ou não.

A compreensão de que o racismo estrutura nossa sociedade e admitir que ele faz parte do cotidiano é um grande passo para entender como as relações étnico-raciais são estabelecidas. Munidos dessa percepção, Almeida (2019) afirma que é preciso a adoção de ações:

Consciente de que o racismo é parte da estrutura social e, por isso, não necessita de intenção para se manifestar, por mais que calar-se diante do racismo não faça do indivíduo moral e/ou juridicamente culpado ou responsável, certamente o silêncio o torna ética e politicamente responsável pela manutenção do racismo (ALMEIDA, 2019, p. 52).

É preciso adotar uma postura ativa diante do racismo, é necessário ser antirracista para questionar e desconstruir essa estrutura sobre a qual se sedimenta a sociedade brasileira. Superar o racismo deve ser compromisso de todos e a escola pode ser espaço privilegiado nesse processo, visto que, como destaca Gomes (2010) grande parte da população brasileira passa boa parte do tempo nessa instituição, e as relações vivenciadas nesse espaço deixam marcas na subjetividade dos sujeitos. Portanto, educar para as relações étnico-raciais passa pela escola e significa assumir o compromisso para a construção de uma sociedade mais justa, democrática e equânime.

\section{ASPECTOS LEGAIS PARA A EDUCAÇÃO DAS RELAÇÕES ÉTNICO-RACIAIS}

A Constituição Federal de 1988, inciso IV do artigo $3^{\circ}$ reconhece enquanto um dos objetivos do país "promover o bem de todos, sem preconceitos de origem, raça, sexo, cor, idade e quaisquer outras formas de discriminação" (BRASIL, 1988, p. 11). Ainda define, no inciso XLII do artigo 50, que "a prática do racismo constitui crime inafiançável e imprescritível, sujeito à pena de reclusão, nos termos da lei" (BRASIL,1988, p.15).

Apesar de crime, o racismo é vivenciado nas diversas relações sociais. Segundo dados divulgados pelo Ministério da Mulher, da Família e dos Direitos Humanos (MMFDH), em 2018 foram recebidas mais de 600 denúncias de discriminação racial pelo Disque 100; e nos dois primeiros meses do ano de 2019 , as denúncias por esse canal tiveram um aumento de $19,46 \%$ se comparados com o mesmo período do ano anterior (BRASIL, 2019).

Outro meio pelo qual o racismo se propaga são as redes sociais, que nada mais é do que o "preconceito real assumido na vida virtual" (BERLEZE; PEREIRA, 2017, p. 1). Porém, para além da dimensão individual, o racismo faz parte de uma estrutura de manutenção de poder que coloca à margem da sociedade as pessoas negras, marcadas historicamente por desigualdades econômicas e sociais.

Reconhecendo a complexidade do racismo brasileiro, Munanga (2005) aponta dois desafios para superá-lo: o primeiro é assumir que o Brasil é um país racista; e o segundo, criar estratégias pedagógicas para combatê-lo no ambiente escolar, visto que "a educação é capaz de oferecer tanto aos jovens como aos adultos a possibilidade de questionar e desconstruir os mitos de superioridade e inferioridade entre grupos humanos que foram introjetados neles pela cultura racista na qual foram socializados" (MUNANGA, 2005, p. 17). Ou seja, o autor reconhece o papel da educação escolar enquanto espaço privilegiado na desconstrução de preconceitos. 
No entanto, a dimensão do racismo que perpassa as instituições sociais permite compreender a escola enquanto reprodutora do racismo. Ao analisar como o sistema escolar vem sendo organizado, Anjos (2005, p. 174) destaca que ele:

tem sido estruturado para a perpetuação de uma ideologia sócio-político-econômica que, junto com os meios de comunicação social, mantém uma estrutura classista, transmissora de valores distorcidos e individualistas. Primeiro, são os livros didáticos, que ignoram o negro brasileiro e o povo africano como agente ativo da formação geográfica e histórica. Em segundo, a escola tem funcionado como uma espécie de segregadora informal.

As colocações de Anjos evidenciam a estrutura do sistema educacional enquanto local de manutenção de privilégios e de reprodução do racismo, pois ao ignorar as inúmeras contribuições do povo negro na formação do Brasil, afasta seu importante papel na formação do povo brasileiro e na construção da nação.

Diante desse panorama, a escola é compreendida enquanto um espaço de tensionamento de forças, instituição sobre a qual é necessário lançar um olhar crítico e esperançoso. Crítico, pois como parte das instituições sociais, reproduz preconceitos; e esperançoso, visto que é um espaço potencial de desconstrução dos mesmos.

Ao reconhecer a educação escolar como uma das formas de lutar contra o preconceito racial, será analisada a legislação brasileira que orienta e normatiza a educação das relações étnico-raciais. Para isso serão verificados os dispostos na Lei no 10.639/2003; na Lei de Diretrizes e Bases da Educação Nacional, Lei no 9.394/96, e nas Diretrizes Curriculares Nacionais para a Educação das Relações Étnico-Raciais e para o Ensino de História e Cultura Afro-Brasileira e Africana (2004).

A Lei no 10.639/03 estabelece as diretrizes e bases da educação nacional, para incluir no currículo oficial da Rede de Ensino a obrigatoriedade da temática 'História e Cultura Afro-Brasileira' (BRASIL, 2003). Essa lei modificou a LDB/96 que teve acrescida a sua redação original os artigos 26-A e 79-B. O primeiro trata da obrigatoriedade do estudo da história africana, afro-brasileira e indígena na formação do Brasil destacando suas contribuições no campo social, político e econômico, que devem ser estudadas nas etapas de ensino fundamental e médio da rede pública e privada sendo ministradas em todo currículo escolar, em especial nas áreas de educação artística, literatura e história brasileira. O segundo estabelece o dia 20 de novembro como o "Dia Nacional da Consciência Negra" no calendário escolar (BRASIL, 1996).

Por último, destaca-se o Parecer n 03/2004, homologado pelo Conselho Nacional de Educação, que instituiu as Diretrizes Curriculares Nacionais para a Educação das Relações Étnico Raciais e para o Ensino de História e Cultura Afro-Brasileira (DCNs). Documento normativo obrigatório, as DCNs são fundamentais para a orientação curricular das instituições de ensino.

A partir de uma leitura histórica, as Diretrizes reconhecem as relações de desigualdades econômicas e sociais que marcaram o lugar social dos escravizados no Brasil e continuam marcando o lugar social dos afrodescendentes de uma forma geral. Conforme as DCNs, as relações étnico-raciais, ou seja, as relações entre negros e não negros são assinaladas pelo preconceito e destacam o papel do Estado brasileiro na correção dessas injustiças, haja vista que:

sem a intervenção do Estado, os postos à margem, entre eles os afro-brasileiros, dificilmente, e as estatísticas o mostram sem deixar dúvidas, romperão o sistema meritocrático que agrava desigualdades e gera injustiça, ao reger-se por critérios de 
exclusão, fundados em preconceitos e manutenção de privilégios para os sempre privilegiados (BRASIL, 2004, p. 11).

Identificadas dentro da historicidade, as relações que privilegiam uns em detrimento de outros são reconhecidas e o racismo é visto enquanto estrutural, pois ele "fornece o sentido, a lógica e a tecnologia para a reprodução das formas de desigualdade e violência que moldam a vida social contemporânea" (ALMEIDA, 2019, p. 21). O rompimento dessa estrutura passa pelo reconhecimento que as diferenças foram utilizadas para estabelecer relações verticais de poder e continuam a se reproduzir no cotidiano.

As DCNs apontam o caminho a ser trilhado para a construção de uma educação antirracista. Para isso, são necessárias "estratégias pedagógicas de valorização da diversidade, a fim de superar a desigualdade étnico-racial presente na educação escolar brasileira, nos diferentes níveis de ensino" (BRASIL, 2004, p. 12). Ou seja, é preciso reconhecer e valorizar a história, cultura e identidade dos afrodescendentes.

Segundo esse documento é preciso que se faça uma educação das relações étnico-raciais a partir de uma pedagogia de combate ao racismo e à discriminação com o objetivo de:

Fortalecer entre os negros e despertar entre os brancos a consciência negra. Entre os negros, poderão oferecer conhecimentos e segurança para orgulharem-se da sua origem africana; para os brancos, poderão permitir que identifiquem as influências, a contribuição, a participação e a importância da história e da cultura dos negros no seu jeito de ser, viver, de se relacionar com as outras pessoas, notadamente as negras. Também farão parte de um processo de reconhecimento, por parte do Estado, da sociedade e da escola, da dívida social que têm em relação ao segmento negro da população, possibilitando uma tomada de posição explícita contra o racismo e a discriminação racial e a construção de ações afirmativas nos diferentes níveis de ensino da educação brasileira. Tais pedagogias precisam estar atentas para que todos, negros e não negros, além de ter acesso a conhecimentos básicos tidos como fundamentais para a vida integrada à sociedade, exercício profissional competente, recebam formação que os capacite para forjar novas relações étnico-raciais (BRASIL, 2004, p. 16-17).

O combate ao racismo só é possível a partir da reconstrução da visão acerca da população negra, do reconhecimento das inúmeras contribuições africanas e afro-brasileiras na formação social, política, econômica e cultural do país. Da compreensão das violências diretas e indiretas que assolou e ainda assola a vida dos negros no Brasil e da luta coletiva em prol da correção de desigualdades.

Para desmontar a estrutura racista e desconstruir preconceitos é necessário conhecimento, e a escola é espaço potente nessa tarefa. Neste sentido, destacamos a necessidade da formação crítica de alunos que sejam capazes de "interferir e promover modificações que conduzam a um clima de verdadeira cidadania e democracia" (LOPES, 2005, p. 187), pois o exercício da cidadania passa pelo reconhecimento das diferenças e comprometimento com a equidade, assim como alerta Santos (2003, p. 53):

Temos o direito de ser iguais quando a nossa diferença nos inferioriza; e temos o direito de ser diferentes quando a nossa igualdade nos descaracteriza. Daí a necessidade de uma igualdade que reconheça as diferenças e de uma diferença que não produza, alimente ou reproduza as desigualdades.

Portanto, infere-se que só é possível falar em igualdade quando há justiça e equidade, pois, as diferenças que caracterizam os grupos humanos foram usadas num jogo de poder no qual pessoas 
de um determinado fenótipo foram escravizadas, coisificadas, subjugadas e injustiçadas e essas relações continuam a se reproduzir no Brasil após 133 anos da abolição oficial da escravidão.

O combate ao racismo e a busca por equidade deve acontecer em diversas frentes e ser compromisso de toda sociedade. Neste sentido, destacamos a importância da legislação educacional que contempla a questão racial, pois é um caminho que aponta para uma escola que reconhece a diversidade, combate às desigualdades e contribui para a formação de uma sociedade que enxerga a pluralidade e a diferença enquanto construtoras de nossa identidade.

As legislações para a construção de uma educação antirracista são importantes ganhos sociais com vistas à correção de desigualdades. Porém, Gomes e Jesus (2013) apontam um conflito na efetivação da Lei no 10.639/2003, visto que enquanto algumas instituições escolares e sistemas de ensino revelam avanços, outros são marcados pela lentidão e até descontinuidade de ações.

Os autores reconhecem que apesar das mudanças em algumas práticas escolares, estas ainda não são suficientes para a superação do racismo em âmbito educacional e embora não haja uniformidade no atendimento à lei, ações pontuais vêm sendo desenvolvidas por algumas instituições.

Para que haja a efetivação de uma educação antirracista é necessário olhar para o documento norteador da escola, o currículo. Ele precisa ser elaborado com o compromisso de educar para as relações étnico-raciais, contribuindo assim, para a construção de uma sociedade antirracista.

\section{DECOLONIZAR O CURRÍCULO PARA COMBATER O RACISMO}

Para iniciar a discussão sobre o currículo é necessário compreendê-lo, Silva (2010) apresenta a etimologia da palavra, proveniente do latim, a palavra curriculum significa pista de corrida e no decorrer dessa corrida as identidades vão sendo construídas. Não se restringindo à transmissão de conteúdo, o currículo também é um discurso que dá corpo a narrativas sobre o indivíduo e a sociedade. Acerca dessas narrativas, Silva, (1995, p. 195), destaca que:

[...] as narrativas contidas no currículo, explícita ou implicitamente, corporificam noções particulares sobre conhecimento, sobre formas de organização da sociedade, sobre os diferentes grupos sociais. Elas dizem qual conhecimento é legítimo e qual é ilegítimo, quais formas de conhecer são válidas e quais não o são, o que é certo e o que é errado, o que é moral e o que é imoral, o que é bom e o que é mau, o que é belo e o que é feio, quais vozes são autorizadas e quais não o são.

Ou seja, o currículo é permeado por relações de poder que tornam possíveis a construção de visões acerca de si e do outro. Partindo do seu reconhecimento enquanto campo de disputa, é necessário questionar que narrativas vêm sendo privilegiadas, quais grupos sociais têm suas vivências e valores enaltecidos, quais sujeitos têm suas vozes ouvidas e quais as tem silenciadas, pois somente a partir da compreensão dessas questões é que novos caminhos podem ser traçados.

Diante disso, serão discutidas possibilidades para a efetivação de uma educação antirracista por meio de um currículo decolonial. Porém, antes da definição do que seria esse currículo decolonial é necessário a compreensão de cinco conceitos: modernidade, colonialismo, descolonização, colonialidade e decolonialidade.

De acordo com Torres (2019), o conceito de modernidade está intimamente ligado ao processo de colonização do continente americano a partir do século XV. Junto com a dominação do território, 
também veio o processo de escravização, não somente dos nativos da América, mas também dos africanos que foram obrigados a sair do seu continente para trabalhar como mão de obra escravizada.

Ainda segundo o autor, o colonialismo está relacionado aos modos empreendidos na "descoberta" do Novo Mundo pelos impérios ocidentais. A descolonização é compreendida como o processo de independência das colônias de suas metrópoles. A colonialidade pode ser entendida como a continuidade de uma lógica de desumanização que permanece após o fim das colônias formais; e a decolonialidade "refere-se à luta contra a lógica da colonialidade e seus efeitos materiais, epistêmicos e simbólicos" (TORRES, 2019, p. 36). A compreensão conceitual fornece lentes para entender que a lógica de poder empreendida a partir da colonização foi atualizada e continua a se reproduzir ainda hoje.

Reconhecer a continuidade da lógica de dominação implementada pela colonialidade, e lutar contra ela é o objetivo principal da decolonialidade. Ao diferenciar os conceitos, Torres (2019, p. 36), aponta que:

colonialidade é uma lógica que está embutida na modernidade, e decolonialidade é uma luta que busca alcançar não uma diferente modernidade, mas alguma coisa maior do que a modernidade [...] enquanto a modernidade ocidental atingiu uma identidade ao inventar uma narrativa temporal e uma concepção de espacialidade que a fez parecer como o espaço privilegiado da civilização em oposição a outros tempos e espaços, a busca por uma outra ordem mundial é a luta pela criação de um mundo onde muitos mundos possam existir, e onde, portanto, diferentes concepções de tempo, espaço e subjetividade possam coexistir e também se relacionar produtivamente.

Entendendo que a colonialidade se reproduz mesmo após o fim da colonização, reconhecemos que ela se expressa por meio de uma relação vertical de poder, onde os dominadores de outrora continuam nas esferas privilegiadas e os dominados permanecem, em sua maioria, na condição de subalternos. Romper com essa estrutura de domínio é um desafio, pois ela se reflete no cotidiano e significa minar as narrativas historicamente construídas acerca do que é certo/errado, feio/bonito, civilizado/incivilizado, conhecimento/não conhecimento. Ou seja, é ultrapassar os limites que estabelecem um padrão de ser, pensar, agir e se posicionar no mundo.

Pensando os aspectos de colonialidade no cotidiano brasileiro e fazendo sua relação com práticas de discriminação racial, Gomes (2019, p. 225) destaca que "o racismo ambíguo brasileiro é um dos pulmões por meio do qual se exala a colonialidade e o colonialismo presentes no imaginário e nas práticas sociais, culturais, políticas e epistemológicas brasileiras". Ou seja, entremeia as relações e instituições sociais.

A colonialidade permanece mesmo após a descolonização e "a mesma se mantém viva em livros didáticos, nos critérios para um bom trabalho acadêmico, na cultura, no senso comum, na autoimagem dos povos, nas aspirações dos sujeitos e em tantos outros aspectos de nossa experiência moderna" (TORRES, 2007, p. 131, tradução nossa). Para que a descolonização seja concretizada, Gomes (2019) ressalta que é necessário que a população negra ocupe os espaços de poder e decisão, tais como os cargos de gestão na saúde, no judiciário, na academia e na educação.

Ao localizar alguns espaços que reproduzem a colonialidade, Gomes (2019, p. 227) destaca que "as escolas da educação básica e o campo da produção científica são alguns deles. Nestes, a colonialidade opera, entre outros mecanismos, por meio dos currículos". Diante disso, pensar a escola e o currículo é condição indispensável para entender como a colonialidade e o racismo se reproduzem nesses 
espaços e como essa instituição pode se transformar em local de práticas decoloniais, inclusivas e emancipatórias a partir de um repensar curricular e um refazer pedagógico.

A colonialidade está enraizada no currículo escolar por meio de práticas como: o conservadorismo das posturas de educadores diante da diversidade presente na escola, seja ela étnica, racial, sexual ou política; a uniformidade de conteúdos selecionados em detrimento das disponibilização de diversas leituras e interpretações acerca da realidade; a seleção de autores com posturas preconceituosas, racistas e/ou xenófobas, sem que haja a devida contextualização e crítica necessária; o não reconhecimento da literatura enquanto produtora de subjetividades; a hierarquização de áreas do conhecimento e disciplinas escolares; o ato de ignorar que o conhecimento é feito sociopoliticamente e o não reconhecimento dos múltiplos mecanismos que interferem no "sucesso" e "fracasso escolar" (GOMES, 2019).

Diante disso, a construção e vivência de um currículo decolonial é um grande desafio, haja vista que a colonialidade que entremeia a sociedade também está presente na escola e se reflete em relações hierarquizadas de conteúdos, saberes e sujeitos escolares revelando a normatização de corpos, a reprodução de preconceitos e o reforço de espaços sociais a serem ocupados pelos indivíduos.

Somem-se às reflexões acima as narrativas construídas acerca das minorias na sociedade e no livro escolar. No artigo intitulado "A desconstrucão da discriminação no livro didático", a professora, pesquisadora e integrante do Movimento Negro Unificado, Ana Célia Silva afirma que "os sujeitos dessas culturas são representados, em grande parte, nos meios de comunicação e materiais pedagógicos, sob forma estereotipada e caricatural, despossuídos de humanidade e cidadania" (SILVA, 2005, p. 21). Quando se pensa sobre a formação do povo brasileiro e nas imagens nos livros de História que retratam os povos apresentados como pilares nessa construção, têm-se cristalizada a imagem do homem branco europeu, ocupando a posição superior de colonizador, e numa posição de inferioridade, o nativo indígena e o africano, na condição de escravizado.

A autora continua suas reflexões acerca de como as minorias, em especial os negros são representados nos livros didáticos afirmando que neles, a criança negra é excluída do processo comunicacional, haja vista que para ela, não há referencial positivo. Ao contrário, é representada com estereótipos inferiorizantes. Não é por acaso que quando é feito um exercício de resgate das imagens dos livros retratando a população negra no período colonial no Brasil, provavelmente serão lembradas as seguintes obras artísticas: Negro no fundo do porão, de Rugendas; Execução de punição por flagelo, Loja de sapateiro e O jantar, de Jean-Baptiste Debret, por exemplo.

A leitura feita a partir da relação moderno/colonial ajuda a entender esse tipo de representação do negro e do branco; seja no material didático, seja nas relações sociais. Em outros termos, se o colonialismo continua a se reproduzir por meio da colonialidade, os processos formativos são hegemonicamente eurocêntricos e estabelecem o que deve ser valorizado e o que não deve ser considerado enquanto relevante; e sobre aquilo que é rebaixado à categoria de insignificância, paira o desconhecimento. Petit (2015) afirma que a história, cultura e contribuições do povo negro é silenciada, e destaca que:

No caso nosso, aqui no Brasil, existe um impressionante desconhecimento, um verdadeiro apagamento histórico relativo às possíveis contribuições culturais da matriz africana nas ciências em geral, inclusive na pedagogia. Junta-se a isso uma espécie de inconsciente coletivo que mantém toda referência ao negro abafada ou silenciada, 
ou extremamente estigmatizada. Em consequência, há uma tendência a se tratar do afrodescendente sempre na terceira pessoa, como o outro (PETIT, 2015, p. 147-148).

Os valores culturais e históricos dos povos africanos contribuíram para a formação do povo brasileiro, porém a invisibilidade dessas contribuições aliadas às representações estereotipadas sobre os corpos, cultura e valores africanos denotam um conjunto de fatores que podem justificar as tentativas de afastamento de uma identidade negra por parte dos sujeitos.

É necessário decolonizar, enegrecer o currículo, possibilitar outras narrativas, dar voz aos que tiveram suas falas sufocadas pelas relações de poder, isso possibilita conhecer o mundo para além dos referenciais brancos europeus que se estabeleceram enquanto norma e implicam diretamente na construção da identidade negra, pois, Carneiro (2005) já alerta que o processo de reconhecimento da negritude é fundamental para que haja uma mobilização política em prol da construção de uma sociedade equânime. Em face disso, a escola precisa efetivamente se engajar na luta antirracista e decolonizar esse documento de identidade, o currículo.

Para uma decolonização curricular é necessário romper com os paradigmas hegemônicos que norteiam o processo educativo, visto que esse é organizado a partir de um conjunto de conhecimentos pautados na racionalidade científica europeia que marca a modernidade. Esse modelo de saber é representado pelo perfil do homem branco, "civilizado", cristão e heterossexual, os seja, o colonizador do continente americano.

São excluídos desse modelo curricular os valores, saberes, histórias e fazeres dos grupos subalternizados durante o período colonial. A forma de ver, organizar e ler o mundo a partir dos parâmetros europeus é colocada enquanto norma. Organizado dessa forma, o currículo reproduz a lógica colonial, e é, portanto, instrumento que colabora com a perpetuação da colonização, pois os saberes pautados a partir de outras visões de mundo são desconsiderados.

Romper com estas práticas curriculares é romper com a colonialidade. É necessário, então, experienciar o conhecimento a partir de bases não eurocêntricas, a partir de outras formas de ser, estar e entender o mundo. Partir de outros referenciais epistêmicos não pautados na norma estabelecida que exalta a racionalidade e desconsidera o corpo enquanto fonte de aprendizagem, que em nome de uma pretensa neutralidade, quer invalidar a subjetividade na produção do conhecimento, que considera a história branca europeia enquanto universal, e desconsidera as realidades locais e as experiências dos indivíduos enquanto válidas para a produção de conhecimento, que invisibiliza e silencia a produção de mulheres, negros e indígenas.

Decolonizar o currículo é resgatar e aprender com as vozes daqueles que, apesar do violento processo de colonização, conseguiram preservar seus costumes, memória, história, outras formas de ser e estar no mundo, ou seja, é possibilitar uma aprendizagem a partir de uma cosmovisão diferente da europeia.

Estes saberes outros podem ser trazidos diretamente para a escola a partir, por exemplo, do estudo da religiosidade afro-brasileira, que tem suas bases fincadas na ancestralidade e cosmovisão africana. O conhecimento desses espaços de fé é uma rica fonte de aprendizado que proporciona a desconstrução de preconceitos que culminam, muitas vezes, em racismo religioso.

Outras ações que a escola pode efetivar é a visitação dos estudantes a comunidades quilombolas e/ou convidar representantes destas comunidades, bem como do movimento negro, para diálogos 
com a comunidade escolar; desnaturalizar os espaços sociais de subalternidade que a população negra ocupa no imaginário social por meio do estudo dos movimentos de resistência durante 0 período colonial através de figuras como Tereza de Benguela, Maria Firmina dos Reis, Esperança Garcia, Adelina (a charuteira), Aqualtune, dentre outras. Apresentar produções negras nos mais diversos campos do conhecimento, como na arte, música, literatura, ciência, tecnologia; levar para a sala de aula a literatura afro-brasileira, ler autores negros.

Essas são apenas algumas, dentre inúmeras práticas pedagógicas que podem ser usadas como um resgate da ancestralidade, da história e memória do povo negro, práticas que decolonizam os seres e os saberes dando voz aos excluídos e permitindo novas possibilidades de construção do conhecimento pautadas na desconstrução de preconceitos e no questionamento das relações de poder.

\section{CONSIDERAÇÕES FINAIS}

Ao olhar para a história é possível perceber que as diferenças que caracterizam os grupos humanos foram utilizadas para estabelecer relações de poder nas quais o padrão branco-europeu foi colocado no topo da escala de valores. Nessas relações, um grupo específico se utilizou como régua para medir, dominar e subjugar o que não era espelho. Pautadas em critérios raciais, formas de ser, existir e estar no mundo diferentes das que eram consideradas enquanto padrão, foram inferiorizadas.

Neste sentido, admite-se que o racismo não é um fenômeno novo, porém vem se atualizando ao passar dos anos e reinventando formas de se reproduzir continuamente, visto que os valores marcados pela colonialidade são reproduzidos nas diversas esferas que compõem o corpo social, inclusive pela escola.

O conhecimento não é neutro, as escolhas didático-pedagógicas também não. Uma educação comprometida com a superação das desigualdades étnico-raciais, conforme estabelecem as Diretrizes Curriculares Nacionais, encontra na perspectiva decolonial possibilidades de sua efetivação. Questionar o que é considerado conhecimento válido, quais são suas bases e quais sujeitos são silenciados, é questionar as estruturas de poder.

Partindo dessa criticidade é possível perceber que as diferenças entre povos e culturas foram utilizadas para estabelecer relações de desigualdade. A partir desse reconhecimento é possível estabelecer um outro olhar e um outro fazer pedagógico a partir das diferenças reconhecendo-as enquanto fontes de conhecimento, de saber.

Nos espaços relacionais, dentre eles a escola, ocorre o que Gomes (2020, p. 32) chama de pedagogia da cor e do corpo, neles "imagens podem ser distorcidas ou ressignificadas, estereótipos podem ser mantidos ou destruídos, hierarquias raciais podem ser reforçadas ou rompidas e relações sociais podem se estabelecer de maneira desigual ou democrática". Espaço que congrega uma diversidade de sujeitos, a escola não pode ser lugar de narrativas únicas, ao contrário, deve ser espaço plural, pois plurais são os corpos que a ocupam. As hierarquias historicamente estabelecidas devem encontrar resistência neste espaço educativo e serem rompidas.

Diante disso, destaca-se a importância de uma escola comprometida com a construção de uma identidade racial positivada a partir da construção e vivência de um currículo decolonial, um currículo 
que ressignifique a história dos africanos e seus descendentes no Brasil, valorizando, por exemplo, seus referenciais culturais, epistêmicos, filosóficos, tecnológicos, religiosos e estéticos.

Com isso, a legislação que normatiza e orienta para a educação das relações étnico-raciais estaria sendo contemplada a partir de um currículo vivo, por meio de uma escola que respeita e acolhe a diversidade dando visibilidade e fala aos sujeitos que foram empurrados historicamente a ocupar o lugar do silêncio. Uma escola comprometida com a formação de sujeitos aptos a construir uma sociedade antirracista e sobretudo, equânime, é uma necessidade histórica e urgente.

\section{REFERÊNCIAS}

ALMEIDA, Silvio Luiz de. Racismo Estrutural. São Paulo: Pólen, 2019.

ANJOS, Rafael Sanzio Araújo dos. A geografia, a África e os negros brasileiros. In: MUNANGA, Kabengele. (Org.). Superando o Racismo na escola. 2 ed. Brasília: Ministério da Educação, Secretaria de Educação Continuada, Alfabetização e Diversidade, 2005. p. 173 - 184.

BERLEZE, Michele.; PEREIRA, Belinda Silva. O racismo nas redes sociais: o preconceito real assumido na vida virtual. In: $4^{\circ}$ Congresso Internacional de Direito e Contemporaneidade: Mídias e Direitos da Sociedade em Rede, 2017, Santa Maria. Anais [...]. Santa Maria: UFSM, 2017. p. 1-14. Disponível em: <http://coral.ufsm.br/congressodireito/anais/2017/1-6.pdf>. Acesso em: 23 mai. 2021.

BRASIL. [Constituição (1988)]. Constituição da República Federativa do Brasil de 1988. Brasília, DF: Presidência da República, [2016]. Disponível em: <https://www2.senado.leg.br/bdsf/bitstream/handle/id/518231/CF88_Livro_EC91_2016.pdf>. Acesso em: 09 mar. 2021.

BRASIL. Decreto no 145, de 11 de julho de 1893. Autorisa o Governo a fundar uma colonia correccional no proprio nacional Fazenda da Boa Vista, existente na Parahyba do Sul, ou onde melhor Ihe parecer, e dá outras providencias. Disponível em: <https://www2.camara.leg.br/legin/fed/decret/1824-1899/decreto-145-11-julho-1893-540923publicacaooriginal-42452-pl.html>. Acesso em: 10 jul. 2021.

BRASIL. Decreto no 528, de 28 de junho de 1890. Regularisa o serviço da introducção e localisação de immigrantes na Republica dos Estados Unidos do Brazil. Disponível em: <https://docs.google.com/document/d/1zbegVY004FyfBfQLZIxvFBaI5QNsiEMAikdfGnJ6c8o/edit>. Acesso em: 12 jul. 2021.

BRASIL. Decreto no 847, de 11 de outubro de 1890. Promulga o Codigo Penal. Disponível em: < http://www.planalto.gov.br/ccivil_03/decreto/1851-1899/d847.htm>. Acesso em: 10 jul. 2021.

BRASIL. Lei de Diretrizes e Bases da Educação Nacional. Brasília, DF: Diário Oficial da União, 1996. Disponível em: <http://www.planalto.gov.br/ccivil_03/leis/l9394.htm>. Acesso em: 02 jul. 2021.

BRASIL. Lei n⿳10.639, de 9 de janeiro de 2003. Brasília, 2003. Altera a Lei no 9.394, de 20 de dezembro de 1996, que estabelece as diretrizes e bases da educação nacional, para incluir no currículo oficial da Rede de Ensino a obrigatoriedade da temática "História e Cultura Afro-Brasileira", e dá outras providências. Diário Oficial da União de 10 jan. 2003. Brasília, DF, 10 jan. 2003. Disponível em: <http://www.planalto.gov.br/ccivil_03/leis/2003/L10.639.htm>. Acesso em: 17 jun. 2021. 
BRASIL. Ministério da Educação. Diretrizes Curriculares Nacionais para a Educação das Relações Étnico-Raciais e para o Ensino de História e Cultura Afro-Brasileira e Africana. Brasília, DF, 2004. Disponível em: <https://www.gov.br/inep/pt-br/centrais-de-conteudo/acervolinha-editorial/publicacoes-diversas/temas-interdisciplinares/diretrizes-curriculares-nacionais-para-aeducacao-das-relacoes-etnico-raciais-e-para-o-ensino-de-historia-e-cultura-afro-brasileira-eafricana>. Acesso em: 02 jul. 2021.

BRASIL. Ministério da Mulher, da Família e dos Direitos Humanos. Divulgação de dados do Disque 100 marcam aniversário da Seppir (2019). Disponível em: <https://www.gov.br/mdh/ptbr/assuntos/noticias/2019/marco/igualdade-racial-aniversario-da-seppir-e-divulgacao-de-dados-dodisque-100-marcam-esta-quinta-feira-21>. Acesso em: 12 jun. 2021.

CARNEIRO. Aparecida Sueli. A Construção do Outro como Não-Ser como fundamento do Ser. 2005. 339 f. Tese (Doutorado em Educação) - Faculdade de Educação da Universidade de São Paulo, São Paulo, 2005. Disponível em: <https://repositorio.usp.br/item/001465832>. Acesso em: 13 jul .2021.

CARVALHO, José Murilo de. Cidadania no Brasil: o longo caminho. 5.ed. Rio de Janeiro: Civilização Brasileira, 2004.

FONTANA, Felipe. Técnicas de pesquisa. In: MAZUCATO, Thiago (Org.). Metodologia da pesquisa e do trabalho científico. Penápolis: FUNEPE, 2018.

FREITAS, Augusto Teixeira de. Consolidação das Leis Civis. Volume I. Brasília: Senado Federal, 2003. Disponível em: <https://www2.senado.leg.br/bdsf/item/id/496206>. Acesso em: 03 jul. 2021.

GOMES, Nilma Lino. Educação, identidade negra e formação de professores/as: um olhar sobre o corpo negro e o cabelo crespo. Educação e Pesquisa, São Paulo, v.29, n.1, p. 167- 182, jan./jun., 2003. Disponível em: <https://www.revistas.usp.br/ep/article/view/27905>. Acesso em: 13 jun. 2021.

GOMES, Nilma Lino. O Movimento Negro e a intelectualidade negra descolonizando os currículos. In: COSTA, Joaze Bernardino et al. (Org.). Decolonialidade e pensamento afrodiaspórico. Belo Horizonte: Autêntica Editora, 2019. p. 223-246.

GOMES, Nilma Lino; JESUS. Rodrigo Ednilson de. As práticas pedagógicas de trabalho com relações étnico-raciais na escola na perspectiva de Lei 10.639/2003: desafios para a política educacional e indagações para a pesquisa. Educar em Revista, Curitiba, Brasil, v.29, n. 47, p. 19-33, jan./mar. 2013. Disponível em: <https://www.scielo.br/scielo.php?pid=S010440602013000100003\&script=sci_arttext $\geq$. Acesso em: 19 mar. 2021.

GOMES, Nilma. Lino. Educação, raça e gênero: relações imersas na alteridade. Cadernos Pagu, n. 6/7, p. 67-82, 1 jan. $2010 . \quad$ Disponível <https://periodicos.sbu.unicamp.br/ojs/index.php/cadpagu/article/view/1862>. Acesso em: 07 fev. 2021.

IBGE. Pesquisa Nacional por Amostra de Domicílios Contínua. Síntese de Indicadores Sociais: em 2019, proporção de pobres cai para $24,7 \%$ e extrema pobreza se mantém em $6,5 \%$ da população. 2020. Disponível: <https://agenciadenoticias.ibge.gov.br/agencia-sala-de-imprensa/2013-agenciade-noticias/releases/29431-sintese-de-indicadores-sociais-em-2019-proporcao-de-pobres-cai-para24-7-e-extrema-pobreza-se-mantem-em-6-5-dapopulacao\#: :text=S\%C3\%ADntese\%20de\%20Indicadores\%20Sociais\%3A\%20em\%202019\%2C 
\%20propor\%C3\%A7\%C3\%A3o\%20de,PPC\%20caiu\%20de\%2025\%2C3\%25\%20para\%2024\%2C7 \%25\%20das\%20pessoas.> Acesso em: 10 jul. 2021.

LOPES, Véra Neusa. Racismo, preconceito e discriminação: Procedimentos didático-pedagógicos e a conquista de novos comportamentos. In: MUNANGA, Kabengele. (Org.). Superando o Racismo na escola. 2 ed. Brasília: Ministério da Educação, Secretaria de Educação Continuada, Alfabetização e Diversidade, 2005. p. 185 - 2014.

MUNANGA, Kabengele. Superando o Racismo na escola. 2 ed. Brasília: Ministério da Educação, Secretaria de Educação Continuada, Alfabetização e Diversidade, 2005.

PETIT, Sandra Haydée. Pretagogia: Pertencimento, Corpo-Dança Afroancestral e Tradição Oral Africana na Formação de Professoras e professores. Fortaleza: EdUECE, 2015.

RIBEIRO, Djamila. Pequeno manual antirracista. São Paulo: Companhia das Letras, 2019.

SANTOS, Boaventura de Sousa. Reconhecer para libertar: os caminhos do cosmopolitanismo multicultural. Rio de Janeiro: Civilização Brasileira, 2003.

SILVA, Ana Célia. A desconstrucão da discriminação no livro didático. In: MUNANGA, Kabengele. (Org.). Superando o Racismo na escola. 2 ed. Brasília: Ministério da Educação, Secretaria de Educação Continuada, Alfabetização e Diversidade, 2005. p. 21 - 37.

SILVA, Tomaz Tadeu da. Documento de Identidade: uma introdução às teorias do currículo. 3. ed. Belo horizonte: Autêntica, 2010.

SILVA, Tomaz Tadeu. Currículo e identidade social: territórios contestados. In. SILVA, Tomaz Tadeu. (Org.). Alienígenas na sala de aula: uma introdução aos estudos culturais em educação. Petrópolis: Vozes, 1995. p. 190-207.

TORRES, Nelson Maldonado. Analítica da colonialidade e da decolonialidade: algumas dimensões básicas. In: COSTA, Joaze Bernardino et al. (Org.). Decolonialidade e pensamento afrodiaspórico. Belo Horizonte: Autêntica Editora, 2019. p. 27-53.

TORRES, Nelson Maldonado. Sobre la colonialidad del ser: contribuciones al desarrollo de un concepto. In: CASTRO-GÓMEZ, S. GROSFOGUEL, R. El giro decolonial: reflexiones para una diversidad epistémica más allá del capitalismo global. Bogotá: Siglo del Hombre Editores; Universidad Central, Instituto de Estudios Sociales Contemporáneos y Pontificia Universidad Javeriana, Instituto Pensar, 2007. p. 127 -168, 2007. Disponível em: <http://www.unsa.edu.ar/histocat/hamoderna/grosfoguelcastrogomez.pdf>. Acesso em: 13 jul. 2021. 